\title{
New frontiers in X-ray spectroscopy in heterogeneous catalysis: Using Fe/ZSM-5 as test-system
}

\author{
W.M. Heijboer, D.C. Koningsberger, B.M. Weckhuysen, F.M.F. de Groot* \\ Department of Inorganic Chemistry and Catalysis, Debije Institute, Utrecht University, \\ Sorbonnelaan 16, 3584 CA Utrecht, The Netherlands
}

Available online 27 October 2005

\begin{abstract}
We have applied a number of novel X-ray spectroscopic tools to Fe/ZSM-5 systems. Fe/ZSM-5 can be considered as an ideal test-system for the characterization techniques in heterogeneous catalysis. The existence of a large range of sites and structures creates a good testing ground to determine which experimental tools are able to resolve such complex system. In situ soft X-ray absorption provides important information on the valence and electronic structure of iron during treatments, with a time scale down to $30 \mathrm{~s}$. K $\beta$-detected XANES yields unprecedented resolution for pre-edge structures and using hard X-rays can be used under any condition and treatment, including high-pressures. It can be expected that both in situ soft X-ray absorption and K $\beta$-detected XANES become 'standard' tools for catalysis research, similar to traditional XANES and EXAFS today. The X-MCD is also used in this paper but it will probably remain a rather specialized technique in the field of heterogeneous catalysis. Further new developments for catalysis characterization are for all to be expected from X-ray spectro-microscopy, where one will have the possibility to perform the in situ soft X-ray absorption and K $\beta$-detected XANES experiments with nanometer size spatial resolution.
\end{abstract}

(C) 2005 Elsevier B.V. All rights reserved.

Keywords: X-ray spectroscopy; XANES

\section{Introduction}

In the paper we focus on the introduction of a number of novel X-ray spectroscopies in the field of heterogeneous catalysis. As a test-system for these techniques we study a number of different Fe/ZSM-5 systems. Fe/ZSM-5 systems are iron-containing MFI-type zeolites. Zeolites have proven to be excellent hosts for active species of transition metals. The metal elements can either be introduced during the zeolite synthesis or through post-synthesis treatments. In the last decade many efforts have been made to develop reproducible preparation routes for active catalysts. Differences in the preparation affect the activity and selectivity for the particular reaction, which most probably is due to a different structure of the active species. However, where the activity of many catalysts is well established, its structure is not always clear. This underlines the need for studies that pay more attention to their characterization. For Fe/ZSM-5, the most frequently studied transition

\footnotetext{
* Corresponding author.

E-mail address: f.m.f.degroot@chem.uu.nl (F.M.F. de Groot).
}

metal zeolite, a variety of structures are proposed for the active site, in particular mono- and binuclear metal species. Below, we outline the characterization of Fe/ZSM-5 samples using novel $\mathrm{X}$-ray spectroscopic techniques. Five techniques will be discussed:

(i) The application of in situ soft X-ray absorption spectroscopy (XAS) in the study of heterogeneous catalysts and a proposal for the detailed data analysis of transition metal spectra.

(ii) The application of X-ray magnetic circular dichroism (XMCD) to heterogeneous catalysts.

(iii) Using a scanning transmission electron microscope (STEM) to measure the electron energy loss (EELS) spectrum, which is equivalent to the soft $\mathrm{X}$-ray absorption spectrum.

(iv) The exploitation of X-ray near edge absorption structure (XANES), in particular the pre-edge structures, by benefiting from high-quality spectra gathered by selective detection methods in hard XAS.

(v) The push of the detection limits in the extended X-ray absorption fine structure (EXAFS) to measure low- 
concentrated Fe/ZSM-5 samples by selective detection and the subsequent refinement of the data analysis.

In the discussion the advantages and disadvantages of these techniques will be discussed, including the implications for the nature of the iron sites in Fe/ZSM-5 systems.

\section{Experimental}

\subsection{Catalyst preparation and characterization}

The preparation of the samples has been discussed in detail elsewhere for the overexchanged Fe/ZSM-5 [1-3] and framework-substituted Fe/ZSM-5 [4]. Framework-substituted Fe/ ZSM-5 was prepared via the hydrothermal synthesis method. $\mathrm{Fe} / \mathrm{ZSM}-5$, with $\mathrm{Si} / \mathrm{Al}=36$ and an iron loading of $0.3 \mathrm{wt} . \%$ (Si/ $\mathrm{Fe}=175)$, as determined by $\mathrm{X}$-ray fluorescence $(\mathrm{XRF})$. Table 1 contains the samples that are used in the X-ray experiments. In the exchange procedure $\mathrm{Fe}$ is anchored onto Brønsted acid sites. The Si/Al ratio of 17 and the iron loading of $4.4 \mathrm{wt} . \%$ ( $\mathrm{Si} /$ $\mathrm{Fe}=17$ ) were determined by ICP analysis. Table 1 contains the names used for the respective samples, including a short description of the treatments. The framework-substituted samples have a label before the name and the overexchanged samples behind. More precise details can be found in the references given above.

Table 1

Samples used in this study

\begin{tabular}{|c|c|}
\hline Name & Treatments \\
\hline \multicolumn{2}{|c|}{ Framework-substituted Fe/ZSM-5 (Si/Al = 36; 0.3 wt.\% Fe) } \\
\hline am-Fe/ZSM-5 & $\begin{array}{l}\text { The as-made crystalline material } \\
\text { was separated by filtration, } \\
\text { washed and dried }\end{array}$ \\
\hline$t f-\mathrm{Fe} / \mathrm{ZSM}-5$ & $\begin{array}{l}\text { The template was removed by } \\
\text { pyrolysis in a dried } \mathrm{N}_{2} \text { flow and } \\
\text { consecutive calcination at } 520{ }^{\circ} \mathrm{C}\end{array}$ \\
\hline $\mathrm{NH}_{4}$ - Fe/ZSM-5 & $\begin{array}{l}\text { The samples were converted into } \\
\text { the } \mathrm{NH}_{4} \text {-form by exchange with } \\
\text { an ammonium nitrate solution and } \\
\text { subsequently they were filtered and dried }\end{array}$ \\
\hline$H-\mathrm{Fe} / \mathrm{ZSM}-5$ & $\begin{array}{l}\text { The H-form was obtained by } \\
\text { calcination at } 520^{\circ} \mathrm{C}\end{array}$ \\
\hline$m s-\mathrm{Fe} / \mathrm{ZSM}-5$ & $\begin{array}{l}\text { A mild steaming with a water partial } \\
\text { pressure of } 200 \mathrm{mbar} \text { in a total flow of } \\
200 \mathrm{ml} / \mathrm{min} \mathrm{N}_{2} \text { at } 600{ }^{\circ} \mathrm{C} \text { for } 2 \mathrm{~h}\end{array}$ \\
\hline$h s-\mathrm{Fe} / \mathrm{ZSM}-5$ & $\begin{array}{l}\text { A hard steaming with a water } \\
\text { partial pressure of } 300 \text { mbar in a } \\
\text { total flow of } 30 \mathrm{ml} / \mathrm{min} \mathrm{N}_{2} \text { at } 550{ }^{\circ} \mathrm{C} \\
\text { for } 4 \mathrm{~h}\end{array}$ \\
\hline \multicolumn{2}{|c|}{ Overexchanged Fe/ZSM-5 (Si/Al = 17; 4.4 wt.\% Fe) } \\
\hline $\mathrm{Fe} / \mathrm{ZSM}-5-\mathrm{Cl}$ & $\mathrm{FeCl}_{3}$ sublimation at $330{ }^{\circ} \mathrm{C}$ \\
\hline $\mathrm{Fe} / \mathrm{ZSM}-5-\mathrm{H}_{2} \mathrm{O}$ & Washed \\
\hline $\mathrm{Fe} / \mathrm{ZSM}-5-\mathrm{mc}$ & $\begin{array}{l}\text { Mild calcination, i.e. slow heating } \\
\text { to } 200{ }^{\circ} \mathrm{C} \text { in helium and after addition } \\
\text { of } \mathrm{O}_{2} \text { continuing to } 550{ }^{\circ} \mathrm{C}\end{array}$ \\
\hline $\mathrm{Fe} / \mathrm{ZSM}-5-\mathrm{sc}$ & Severe calcination in $\mathrm{O}_{2}$ at $550{ }^{\circ} \mathrm{C}$ \\
\hline
\end{tabular}

Given are the names and, in short, the treatments applied.

\subsection{Experimental techniques}

\subsubsection{In situ soft X-ray absorption spectroscopy}

The soft X-ray absorption spectra (XAS) of the iron L edge were measured at BESSY (Berlin, Germany), beamlines U49/ 2-PGM-1 and UE56/2-PGM-1 [3,5]. The spectral resolution of the monochromators was approximately $0.2 \mathrm{eV}$. The instrumentation for in situ low energy XAS experiments has been developed by Knop-Gericke et al. and is described in detail elsewhere [6,7]. The X-ray absorption spectral shape was measured at 5 mbar gas pressure with ionized-gas-conversion total-electron-yield, which has a probing depth of approximately $4 \mathrm{~nm}$ [8].

\subsection{2. $X-M C D$ experiments}

The X-MCD measurements were conducted using beamline 4.0.2 at the ALS (Berkeley, USA). The samples were measured in vacuum at $4 \mathrm{~K}$ using a $6 \mathrm{~T}$ superconducting magnet, in order to magnetize the paramagnetic centres. The resolution of the monochromator is better than $0.2 \mathrm{eV}$ and for the fluorescence measurements a Canberra 30-element Ge detector was used $[9,10]$.

\subsubsection{STEM-EELS}

The VG-HB501 STEM equipped with a field-emission gun and a parallel Gatan 666 electron EELS detector at the Laboratoire de Physique Solide (LPS) in Orsay, France has been used to measure the iron L edge and the oxygen K edges of the iron in overexchanged ZSM-5. This provides spectroscopic information (including the chemical composition) with a spatial resolution of $0.5 \mathrm{~nm}$ and an energy resolution of $0.7 \mathrm{eV}$. It can be shown that EELS spectra obtained in an electron microscope are identical to the X-ray absorption spectra [11].

\subsection{4. $K \alpha$ - and $K \beta$-detected $X A F S$}

The $K \alpha$ - and $K \beta$-detected XANES spectra have been measured on the BioCAT undulator beamline 18-ID [12] at the APS synchrotron (Argonne, USA). The samples have been measured in an in situ reactor cell at 25 to $350{ }^{\circ} \mathrm{C}$ under ( 1 bar) controlled gas conditions. The energy bandwidth of the incident $\mathrm{X}$-ray beam was approximately $1.2 \mathrm{eV}$ and the (maximum) incident flux was 10 photons/s [13]. The $\mathrm{K} \beta$ fluorescence emission from the samples was measured with $0.8 \mathrm{eV}$ resolution by a crystal array spectrometer, using six spherically bent Ge(6 20$)$ crystals. The $\mathrm{K} \alpha$ spectra were measured with $0.8 \mathrm{eV}$ resolution using four spherically bent $\mathrm{Ge}(440)$ crystals $[13,14]$. High-resolution K $\alpha$-detected XANES spectra were recorded by tuning the emission analyzer energy to the maximum intensity of the $\mathrm{Fe} \mathrm{K} \alpha$-lines of $\mathrm{Fe}_{2} \mathrm{O}_{3}$ and by scanning the incident energy through the XANES region. This procedure is referred to as a constant emission energy (CEE) scan. The same emission energy was used for all Fe/ZSM-5 measurements. Conventional absorption spectra were obtained by integrating the $\mathrm{K} \alpha$ fluorescence over $25 \mathrm{eV}$. This corresponds to recording the total fluorescence yield, which identifies with a conventional absorption spectrum. $\mathrm{K} \alpha-$ detected EXAFS spectra were recorded by tuning the emission 
Table 2

Comparison of the conditions of the various experimental tools applied

\begin{tabular}{|c|c|c|c|c|c|}
\hline & $T(\mathrm{~K})$ & $P$ (bar) & Detection & Depth (nm) & Concentration (wt.\%) \\
\hline Soft XAS & $300-623$ & 0.005 & Electron yield & 4 & 1.0 \\
\hline X-MCD & 4 & $<10^{-10}$ & Fluorescence & 1,000 & $<0.1$ \\
\hline STEM-EELS & 300 & $<10^{-10}$ & Transmission & 100 & 1.0 \\
\hline $\mathrm{K} \beta-\mathrm{XAFS}$ & $77-623$ & 1 & Fluorescence & 500,000 & $<0.1$ \\
\hline
\end{tabular}

Given are the temperature $(T)$, pressure $(P)$, detection technique, probing depth and lowest detectable concentration (see text).

analyzer energy to the maximum intensity of the $\mathrm{Fe} \mathrm{K} \alpha$ lines of $\mathrm{Fe}_{2} \mathrm{O}_{3}$ and by scanning the incident energy through the XANES and EXAFS region. The scans have been taken up to $700 \mathrm{eV}$ above the edge $\left(E_{0}=7112 \mathrm{eV}\right)$ and for each catalyst sample at least 90 scans were averaged (Table 2).

\section{Results}

\subsection{In situ soft $X$-ray absorption spectroscopy}

We have applied soft X-ray absorption spectroscopy to $\mathrm{Fe} /$ ZSM-5. Soft X-ray absorption spectroscopy on 3d metal edges is one of the main techniques in the field of solid-state physics, in particular of correlated transition metal oxide systems. In the field of heterogeneous catalysis it has been little used, partly due to the difficulty of in situ measurements.

The iron L edge was measured of Fe/ZSM-5-mc under $\mathrm{O}_{2}$ and helium at $350{ }^{\circ} \mathrm{C}$ (Fig. 1). One observes a clear shift of the peak maximum from 708 to $709.5 \mathrm{eV}$. From comparison to the iron-oxide compounds and charge transfer multiplet calculations, we can conclude that these two spectra relate respectively

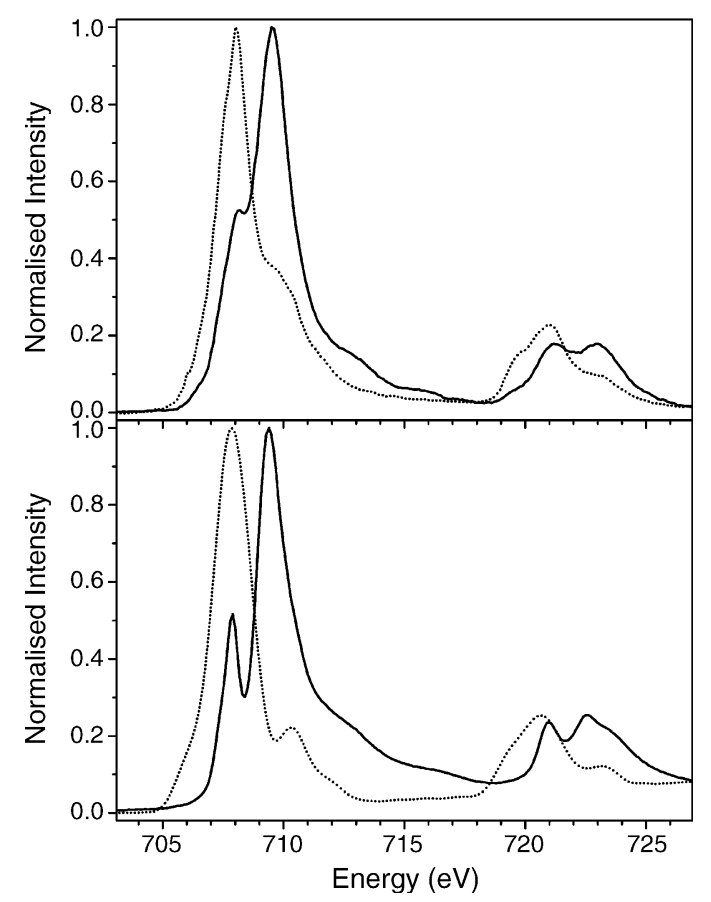

Fig. 1. Bottom: Fe L edge spectra of $\mathrm{Fe}_{2} \mathrm{O}_{3}$ (solid line) and $\mathrm{FeAl}_{2} \mathrm{O}_{4}$ (dotted line). Top: Fe L edge spectra of oxidized (solid line) and reduced (dotted line) Fe/ZSM-5-mc to pure $\mathrm{Fe}^{\mathrm{III}}$ and $\mathrm{Fe}^{\mathrm{II}}$. The calculations show that the $\mathrm{Fe}^{\mathrm{III}}$ site is octahedral with a crystal field of approximately $1.0 \mathrm{eV}$. This is less then the crystal field of $1.5 \mathrm{eV}$ for $\mathrm{Fe}_{2} \mathrm{O}_{3}$, indicating weaker iron-oxygen bonds in the zeolite. The $\mathrm{Fe}^{\mathrm{II}}$ site is tetrahedral with a crystal field of $-1.0 \mathrm{eV}$, which is similar to the bulk oxide $\mathrm{FeAl}_{2} \mathrm{O}_{4}$. The spectra thus show a transition from six-fold $\mathrm{Fe}^{\mathrm{III}}$ to four-fold $\mathrm{Fe}^{\mathrm{II}}$ under oxidized respectively reduced conditions [5].

We monitored the $\mathrm{Fe}$ oxidation/reduction behaviour in overexchanged Fe/ZSM-5, prepared by chemical vapour deposition of $\mathrm{FeCl}_{3}$, as a function of heat treatment and gas atmosphere. We developed a fast valence determination method based on the shape and position of the $\mathrm{Fe}_{3}$ edge in the range from 703 to $714 \mathrm{eV}$. The measurement of $\mathrm{L}_{3}$ edge takes about $1 \mathrm{~min}$, which provides a good time resolution to follow the changes in the average valence of Fe with temperature and gas environment.

Fig. 2 shows that the Fe/ZSM-5 system is an extremely flexible system, with regard to the valence of iron under various conditions. We find that, at a total pressure of 2 mbar, Fe/ZSM-5$\mathrm{mc}$ has an average valence of 2.9 in $\mathrm{O}_{2}$ (5\% in helium) - both at room temperature and at $350{ }^{\circ} \mathrm{C}$, of 2.5 under helium at room temperature, and of 2.1 , respectively, 2.5 under helium at $350{ }^{\circ} \mathrm{C}$ depending on the sample history. The Fe/ZSM-5-sc sample shows values that are approximately $0.05-0.15$ larger. This higher average valence is in agreement with observations that part of the iron in the Fe/ZSM-5-sc sample is positioned in small iron-oxide nanoparticles at the outer surface of the zeolite crystals (see below). Such iron-oxide nanoparticles, which are more difficult to reduce than the iron clusters inside the Fe/ZSM5 , seem to constitute only a minor part of the total Fe amount.

An interesting phenomenon in Fig. 2 is that overshoot effects accompany the changes in the iron valence. During heating in helium, the valence typically reaches a minimum value, for example at $t=290$, before slightly rising again, while the temperature is constant. A similar effect occurs during autoreduction in helium at a fixed temperature of $25^{\circ} \mathrm{C}$. These overshoot effects are ascribed to surface versus bulk kinetic phenomena, where we note that we see only the iron atoms in the top $4 \mathrm{~nm}$ of the samples.

It turned out that the in situ soft X-ray absorption spectra measured on the framework-substituted Fe/ZSM-5 samples did not have enough statistics to analyze their spectral shapes. It turns out that the measurement of $0.3 \mathrm{wt} . \%$ iron samples is too difficult in the present set-up. The soft X-ray absorption spectra of low loaded samples can be measured with fluorescence yield detection as will be discussed below. 


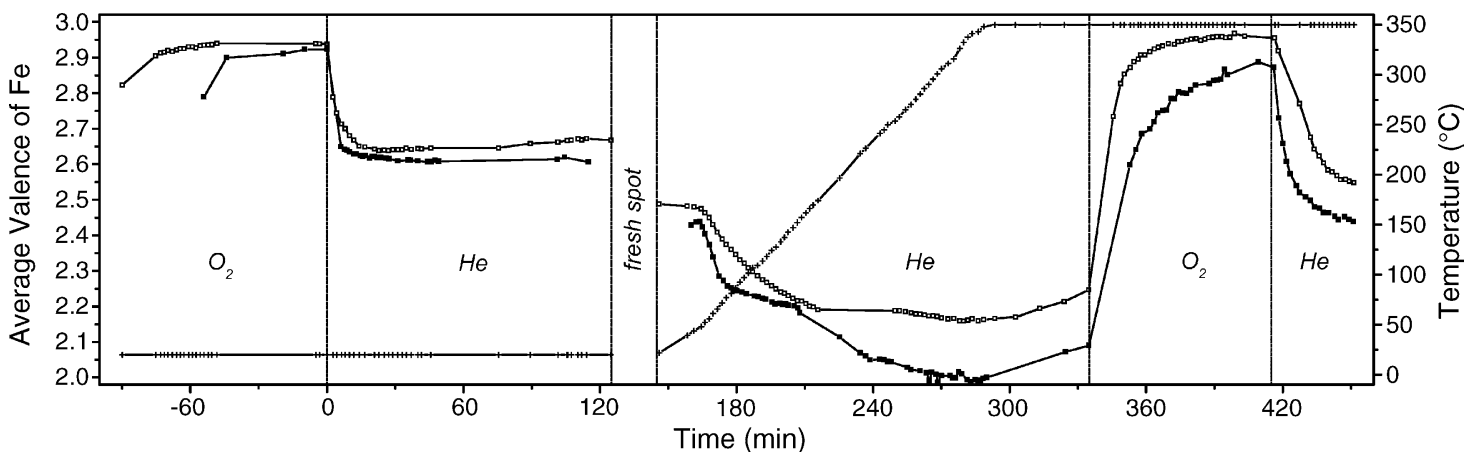

Fig. 2. Series of treatments of Fe/ZSM-5-sc $(\square)$ and Fe/ZSM-5-mc $(\square)$. The respective treatments are the oxidation in $\mathrm{O}_{2}[-90,0]$, autoreduction in He [0, 150], heating (indicated with + ) in $\mathrm{He}$ to $350{ }^{\circ} \mathrm{C}$ [150, 290], $\mathrm{He}$ at $350{ }^{\circ} \mathrm{C}[290,340], \mathrm{O}_{2}$ at $350{ }^{\circ} \mathrm{C}[340,410]$ and $\mathrm{He}$ at $350{ }^{\circ} \mathrm{C}$ [410, 450]. All times given in minutes.

\section{2. $X-M C D$}

$\mathrm{X}$-ray magnetic circular dichroism $(\mathrm{X}-\mathrm{MCD})$ is a major characterization tool for ferromagnetic metals, oxides and their surfaces and for paramagnetic sites in bio-inorganic chemistry and coordination compounds [10]. Heterogeneous catalysts contain low-loaded metal sites that form isolated sites or clusters. In addition to the spectral shape analysis that can provide the local symmetry and bonding, the X-MCD spectrum gives extra information that is very important for Fe/ZSM-5 systems, as will be explained below. The X-MCD signal is provided by all aligned magnetic moments in a certain system. Assuming a paramagnetic system of isolated moments, full magnetization can be obtained. In contrast a binuclear $\left(\mathrm{Fe}^{\mathrm{III}}\right)$ centre will couple anti-ferromagnetically, which thereby cancels its MCD effect. Also iron-oxide particles will be anti-ferromagnetic (or weakly ferrimagnetic). These observations create an important new tool: The magnitude of the XMCD effect can be directly related to the amount of single iron sites, where quantitatively there could be a small correction factor due to partial magnetization of small iron-oxide particles. The X-MCD spectral shapes will be published elsewhere [15] and Table 3 contains the results regarding the amount of $\mathrm{Fe}^{\mathrm{II}}$ and the amount of magnetized iron.

It turns out that all iron in $\mathrm{am}$-Fe/ZSM-5 is trivalent and from the X-MCD spectral shape it is found that iron occupies dominantly six-fold sites. These six-fold sites will be framework sites that are originally tetrahedral, but additional bonding occurs in the am-Fe/ZSM-5. Also the fact that the measurements take place at $4 \mathrm{~K}$ could influence the coordination. The $\mathrm{X}-\mathrm{MCD}$ signal is exactly equal to its theoretical maximum, which implies that all the paramagnetic iron sites have been aligned and that all iron occupies isolated iron sites. After

Table 3

Distribution of magnetic Fe species in framework-substituted Fe/ZSM-5 samples, as derived from $\mathrm{X}-\mathrm{MCD}$

\begin{tabular}{llclc}
\hline & Isolated $(\%)$ & Clusters $(\%)$ & $\mathrm{Fe}^{\mathrm{III}}(\%)$ & $\mathrm{Fe}^{\mathrm{II}}(\%)$ \\
\hline$a m$-Fe/ZSM-5 & 95 & 5 & 95 & 5 \\
$H$-Fe/ZSM-5 & 70 & 30 & 70 & 30 \\
$h$-Fe/ZSM-5 & 50 & 50 & 80 & 20 \\
\hline
\end{tabular}

All numbers have an uncertainty of $\pm 10 \%$. calcination the $H$-Fe/ZSM-5 sample is partly reduced to $\mathrm{Fe}^{\mathrm{II}}$. The X-MCD signal reaches $70 \%$ of its maximal value indicating that $30 \%$ of the iron occurs in clusters. The $h s-\mathrm{Fe} /$ ZSM-5 sample shows a 50\% reduced X-MCD signal, indicating that half the iron atoms form antiferromagnetic pairs or larger antiferromagnetic aggregates, where $20 \%$ of the iron is reduced to $\mathrm{Fe}^{\mathrm{II}}$. The measurements are performed at $4 \mathrm{~K}$ under vacuum conditions, which will influence the iron valence. We therefore do not attempt to quantify the average valence from the X-MCD measurements. The interesting result is that in $H$-Fe/ZSM-5 we have $30 \%$ clusters and in $h s$-Fe/ZSM-5 even 50\%. These results will be compared with the hard X-ray (EXAFS) results below.

\subsection{STEM-EELS}

Fig. 3 shows a STEM image from Fe/ZSM-5-sc. On the right the zeolite crystal is visible. On the outside of the big zeolite particle, small particles are visible. The EELS spectra of one such particle are shown in Fig. 4.

Fig. 4 shows the EELS spectra of the nanoparticles on the outside surface of Fe/ZSM-5-sc sample. From comparison to reference compounds, it can be concluded that these spectra correspond to $\mathrm{Fe}_{2} \mathrm{O}_{3}$. Other possible iron oxide systems such as

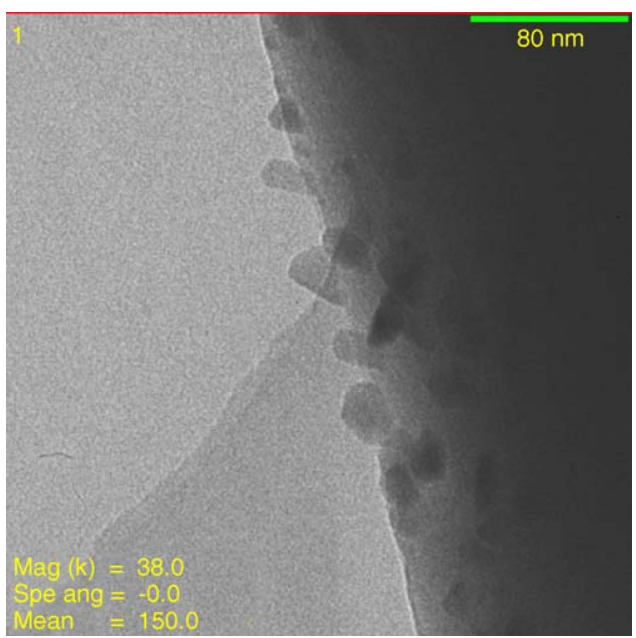

Fig. 3. STEM image of Fe/ZSM-5-sc. The size of the image is $300 \times 300 \mathrm{~nm}$. The size of the small nanoparticles is up to approximately $10 \times 30 \mathrm{~nm}$. 

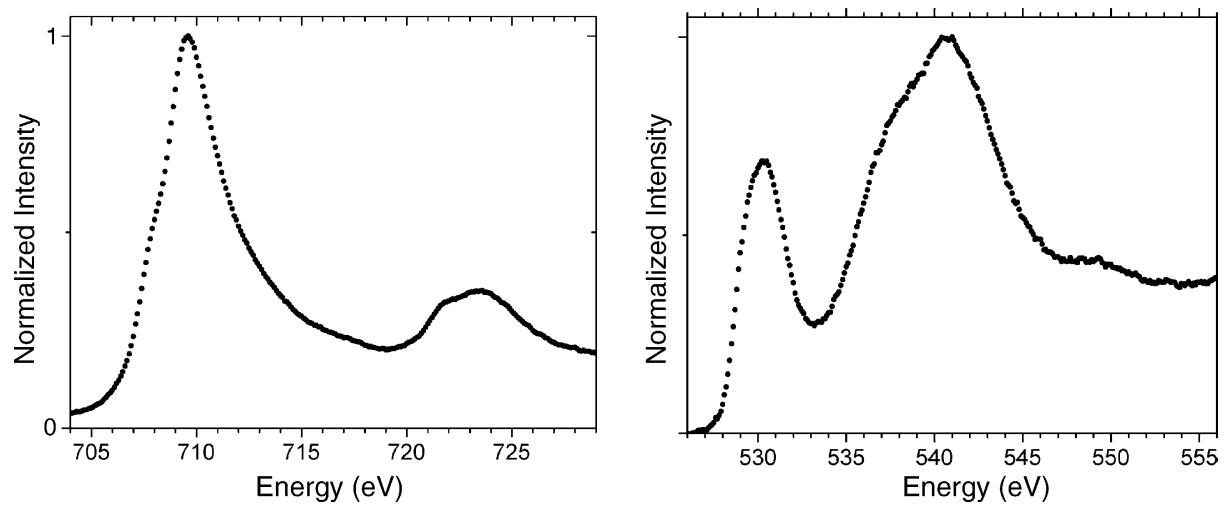

Fig. 4. The iron L edge (left) and oxygen K edge (right) EELS spectrum of a nanoparticle on the outside surface of Fe/ZSM-5-sc. The EELS spectra have an intrinsic spatial resolution of $0.5 \mathrm{~nm}$ and have been integrated over the particle area.

$\mathrm{Fe}_{3} \mathrm{O}_{4}$ and $\mathrm{FeO}(\mathrm{OH})$ have significantly different oxygen and iron spectra and can be excluded. It should be noted that the STEM-EELS spectra have not been measured in situ, implying that the nanoparticles could have been modified under ambient conditions, where it is noted that $\mathrm{Fe}_{3} \mathrm{O}_{4}$ and $\mathrm{FeO}(\mathrm{OH})$ should be stable under such conditions. The advantage of STEM-EELS, compared with XAS, is that one measures a single nanoparticle with a spatial resolution of $0.5 \mathrm{~nm}$. Soft X-ray microscopes are improving their spatial resolution, but at present a $20 \mathrm{~nm}$ spotsize is the limit. These EELS spectra confirm an earlier assignment of these particles by Battiston et al., based on the iron-oxygen intensity ratio. Battiston et al. found a uniform distribution of iron in $\mathrm{Fe} / \mathrm{ZSM}-5-\mathrm{H}_{2} \mathrm{O}$, some iron aggregation in Fe/ZSM-5-mc and iron oxide nanoparticles in Fe/ZSM-5-sc [1].

\section{4. $K \alpha$ - and $K \beta$-detected $X A F S$}

The K edge XAFS spectra of the $3 d$ transition metals are a well-known probe to study heterogeneous catalysts. The EXAFS region is used to determine the nature of the neighbours, their number and their distances. This will be discussed below. The energy position of the K edge varies with the valence, at least if the structure and the nature of the neighbours do not vary too much. The pre-edge region gives valuable information for the determination of the average valence and site symmetry of the iron sites. It has been shown that the energy position of the centroid is related to the valence and that the integrated intensity is related to the site symmetry, where the determination of both these quantities depends crucially on the proper isolation of the pre-edge from the edge.

$\mathrm{K} \alpha$ - and $\mathrm{K} \beta$-detected XAFS makes use of a high-resolution $\mathrm{X}$-ray emission detector. This has the consequence that the as such measured XANES part of the spectrum has a much improved resolution. This can be mainly ascribed to the effective replacement of the $1 \mathrm{~s}$ core hole lifetime broadening of $1.5 \mathrm{eV}$ by the $2 \mathrm{p}$ or $3 \mathrm{p}$ lifetime broadening of $0.3 \mathrm{eV}$, which is a consequence of the fact that X-ray absorption and X-ray emission occur coherently. For the pre-edge and edge analysis, we measured the fluorescent $3 \mathrm{p}$ to $1 \mathrm{~s}(\mathrm{~K} \beta)$ transition with $1.0 \mathrm{eV}$ resolution. The better resolved spectra enabled a refined analysis of in particular the pre-edge feature. Fig. 5 shows the differences in the pre-edge spectra measured by conventional XANES (bottom) and K $\beta$-detected XANES (top). The measurement of thus well-resolved pre-edge features that, in addition, are well separated from the main absorption edge implied a significant improvement of the determination of the energy position of the centroid and its integrated intensity, the main parameters for the characterization of the pre-edge feature [16].

Fig. 6 shows the changes in the integrated pre-edge intensity versus and the centroid position for iron in different Fe/ZSM-5 samples. The characteristics of the reference iron oxide compounds with known valence and local coordination of iron are also plotted. The energy position of the centroid does not differ much for the Fe/ZSM-5 samples. The energy positions are about $0.2 \mathrm{eV}$ to higher energy with respect to the $\mathrm{Fe}^{\mathrm{III}}$ references, indicating an essentially completely oxidized $\mathrm{Fe}^{\mathrm{III}}$ in all samples under these conditions, i.e. in a flow of 7.7 vol. $\% \mathrm{O}_{2}$.

From Fig. 6, the influence of activation treatments on the iron in framework-substituted Fe/ZSM-5 is clearly visible. The integrated pre-edge intensity of the pre-edge relative to the main edge is decreasing upon progressive treatments from amFe/ZSM-5 to $h s$-Fe/ZSM-5. The peak shape and energy position remains similar. To make a quantification of the amount of

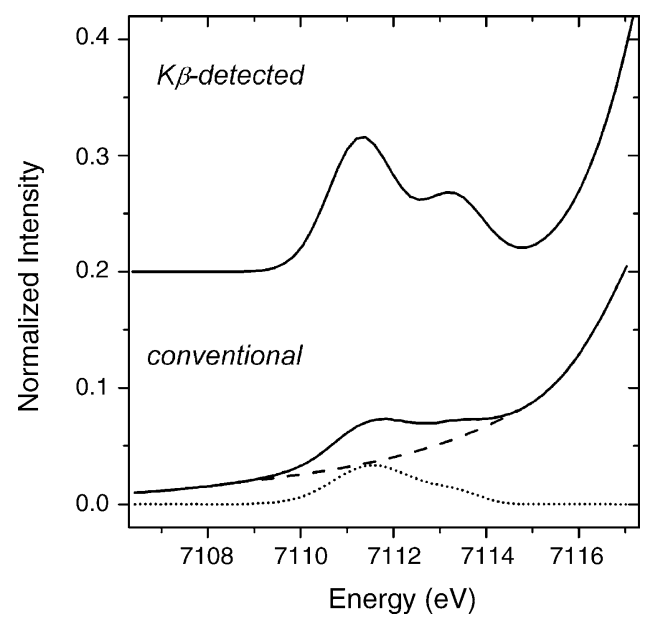

Fig. 5. Fe K pre-edge feature of fayalite $\left(\mathrm{Fe}_{2} \mathrm{SiO}_{4}\right)$. Bottom: conventional XANES spectrum (solid) divided into the main edge (dash) and the as-such isolated pre-edge (dot). Top: K $\beta$-detected XANES spectrum. 


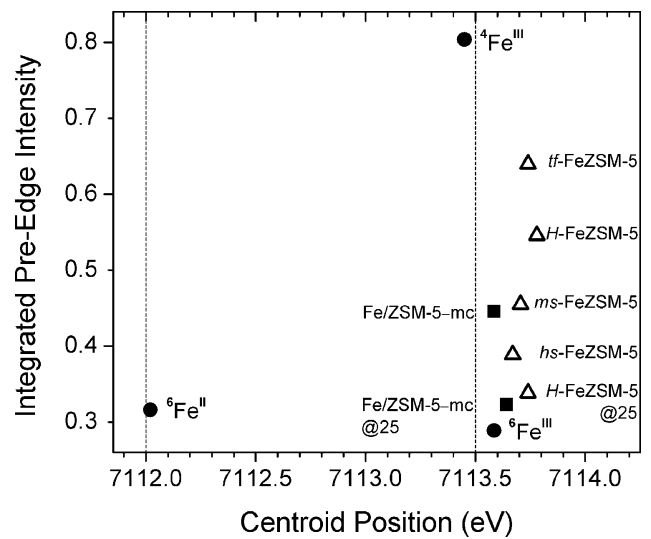

Fig. 6. Integrated pre-edge intensity vs. centroid position for iron in different Fe/ZSM-5 samples in a flow of $\mathrm{O}_{2}(7.7 \mathrm{vol} . \%$ in $\mathrm{He})$ at 350 or $25^{\circ} \mathrm{C}$ (indicated with @25). The pre-edge characteristics are also given for iron model compounds: $\mathrm{FePO}_{4}={ }^{4} \mathrm{Fe}^{\mathrm{III}}, \alpha-\mathrm{Fe}_{2} \mathrm{O}_{3}={ }^{6} \mathrm{Fe}^{\mathrm{III}}$ and $\mathrm{Fe}_{2} \mathrm{SiO}_{4}={ }^{6} \mathrm{Fe}^{\mathrm{II}}$.

tetrahedral $\mathrm{Fe}$, first the assumption is made that the symmetries of iron in $\mathrm{FePO}_{4}$ and in $\mathrm{Fe}_{2} \mathrm{O}_{3}$ represent the practical extremes for the possible coordination of iron species in Fe/ZSM-5. They are assumed to be equivalent to isomorphous substitution for silicon in the $\mathrm{Td}$ sites of the zeolite framework, respectively fully extracted six-fold coordinated by oxygen. To quantify the results, we further assume that the integrated intensity is a linear combination of the two $\mathrm{Fe}^{\mathrm{III}}$ references. This procedure is feasible because the pre-edge integrated intensity is proportional to the degree of distortion from the centrosymmetric coordination of the transition metal element. We note that some care must be taken, because other effects, for example shorter $\mathrm{Fe}-\mathrm{O}$ distances. Using this quantification, we find that in $t f$-Fe/ZSM-5, $35 \%$ of the iron is already in six-fold coordination, increasing to $50 \%$ in $H$-Fe/ZSM-5. Steaming further increases the six-fold sites to $68 \%$ in $m s-\mathrm{Fe} / \mathrm{ZSM}-5$ and $80 \%$ in $h s$-Fe/ZSM-5. Cooling down to $25^{\circ} \mathrm{C}$ yields almost pure six-fold sites for both $H$-Fe/ ZSM-5 and the overexchanged Fe/ZSM-5-mc sample, in agreement with the X-MCD measurements at $4 \mathrm{~K}$ that also found essentially six-fold coordination. This implies that at lower temperatures the unsaturated iron sites take up oxygen neighbours from water. The Fe/ZSM-5-mc sample at $350{ }^{\circ} \mathrm{C}$ has a similar amount $(70 \%)$ of six-fold sites as $m s$-Fe/ZSM-5.

We conclude that this analysis of the K $\beta$-detected XANES allows to quantify the degree of iron extraction out of the zeolite framework as a function of the treatments, where we note that a number of $35 \%$ six-fold coordination does not necessarily imply that $35 \%$ of the irons has six-fold coordination and $65 \%$ has four-fold. Instead it is much more likely that most iron sites will be intermediate between pure four-fold and pure six-fold, as will be further quantified in the EXAFS analysis.

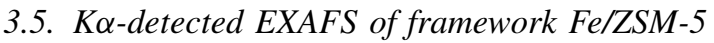

Using $\mathrm{K} \alpha$-detected fluorescence detection does not alter the EXAFS signal apart from low (essentially zero) background. Due to the low intrinsic noise, the signal-to-noise ratio of this detection scheme was very good and allowed for good quality in situ experiments on $0.3 \mathrm{wt} . \%$ Fe/ZSM-5 samples.
Table 4

The averaged coordination parameters of the first oxygen and metal shells obtained by an $R$-space fit of the EXAFS data measured in $\mathrm{O}_{2}$ at $350{ }^{\circ} \mathrm{C}$

\begin{tabular}{lcc}
\hline & $\langle N\rangle$ & $\langle\mathrm{R}\rangle(\AA)$ \\
\hline$t f-\mathrm{Fe} / \mathrm{ZSM}-5$ & & \\
$\mathrm{Fe}-\mathrm{O}$ & 4.0 & 1.85 \\
$\mathrm{Fe}-\mathrm{Si} / \mathrm{Al}$ & 4.0 & 2.88 \\
$\mathrm{H}$-Fe/ZSM-5 & & \\
$\mathrm{Fe}-\mathrm{O}$ & 4.0 & 1.91 \\
$\mathrm{Fe}-\mathrm{Si} / \mathrm{Al}$ & 4.0 & 2.86 \\
$\mathrm{~h}-\mathrm{Fe} / \mathrm{ZSM}-5$ & & \\
$\mathrm{Fe}-\mathrm{O}$ & 4.9 & 1.94 \\
$\mathrm{Fe}-\mathrm{Al}$ & 4.1 & 3.10 \\
$\mathrm{Fe}-\mathrm{Fe}$ & 3.7 & 3.17 \\
\hline
\end{tabular}

Table 4 gives part of the results of the EXAFS analysis. The full results and detailed analysis have been given elsewhere [15]. It can be seen that $t f-\mathrm{Fe} / \mathrm{ZSM}-5$ measured in $\mathrm{O}_{2}$ at $350{ }^{\circ} \mathrm{C}$ can be fitted with a four-fold surrounding of oxygen that is slightly distorted. This distortion increases for $H$-Fe/ZSM-5. The association of a proton to the framework also leads to the formation of an $\mathrm{OH}$-group and a rearrangement of electron density, resulting in a longer $\mathrm{Fe}-\mathrm{O}$ bond (from 1.85 to $1.91 \AA$ ). In case of $h s$-Fe/ZSM-5 a new situation arises with on average approximately five oxygen neighbours and, more importantly, its first metal shell containing almost four iron atoms. This suggests that part of the iron in $h s-\mathrm{Fe} / \mathrm{ZSM}-5$ occurs in rather large iron-oxide clusters. The EXAFS analysis suggests that these iron-oxide nanoparticles contain significant amounts of $\mathrm{Al}$, suggesting iron-aluminium-oxide structures.

\subsection{EXAFS analysis of overexchanged Fe/ZSM-5}

The overexchanged Fe/ZSM-5 has been measured with EXAFS by Battiston et al.. They assumed only iron as nonoxygen neighbours in the EXAFS fits. In light of the new results as discussed above, a second analysis has been performed, where in addition to iron also the $\mathrm{Si}$ and $\mathrm{Al}$ of the framework is included. Table 5 compares the values for the amount of iron neighbours of both models. It can be observed that in model 2, both $\mathrm{Fe} / \mathrm{ZSM}-5-\mathrm{Cl}$ and $\mathrm{Fe} / \mathrm{ZSM}-5-\mathrm{H}_{2} \mathrm{O}$ can be fitted without iron. The same fit-procedure then yields considerably higher iron neighbours for the Fe/ZSM-5-mc and Fe/ZSM-5-sc samples. These two fits have equal quality and the overall fit

Table 5

Fit results for overexchanged Fe/ZSM-5 samples using only iron as non-oxygen neighbours (=model 1) and using the framework $\mathrm{Si}$ and $\mathrm{Al}$ in addition to iron as non-oxygen neighbours (=model 2)

\begin{tabular}{lll}
\hline & $N(\mathrm{Fe})$ (model 1) & $\begin{array}{l}N(\mathrm{Fe}) \\
(\text { model 2) }\end{array}$ \\
\hline Fe/ZSM-5-Cl & 0.3 & 0.0 \\
Fe/ZSM-5- ${ }_{2} \mathrm{O}$ & 1.0 & 0.0 \\
Fe/ZSM-5-mc & 1.6 & 2.5 \\
Fe/ZSM-5-sc & 2.9 & 5.1 \\
\hline
\end{tabular}

Both fits have equal quality. 
is very accurate [15]. As such, both models can be seen as extremes with regard to the amount of iron. We therefore can conclude that the amount of iron neighbours increases from $0-0.3$ in Fe/ZSM-5-Cl and 0-1.0 in Fe/ZSM-5- $\mathrm{H}_{2} \mathrm{O}$, to 1.6-2.5 in Fe/ZSM-5-mc and 2.9-5.1 in Fe/ZSM-5-sc. It turns out that the omission of $\mathrm{Si}$ and $\mathrm{Al}$ also lowers the amount of iron in those cases where significant amounts of iron are present.

\section{Discussion}

\subsection{Main identified iron species in Fe/ZSM-5}

As we have seen above, the characterization of the molecular structure of the active site in Fe/ZSM-5 catalysts is complicated by the presence of various phases. The identification of the structures requires the accurate determination of key characteristics as the oxidation state and the local coordination. No single characterization technique is able to provide a final answer for the structure of the Fe site(s) in Fe/ZSM-5 catalysts. Main issues in the characterization of Fe/ZSM-5 are reducibility, local Fe environment, nuclearity of the Fe species and the structural changes observed during treatments and reactions. According to literature, the main identified species present in Fe/ZSM-5 can be classified as follows:

(a) single framework Fe sites, $\mathrm{Fe}_{\mathrm{F}}$ (framework),

(b) isolated, single extraframework Fe sites, $\mathrm{Fe}_{1}$ (mononuclear),

(c) oxo-bridged extraframework Fe centres, $\mathrm{Fe}_{2}$ (binuclear),

(d) chain-like structures of extraframework $\mathrm{Fe}, \mathrm{Fe}_{\mathrm{N}}$ (oligomeric),

(e) aggregates of extraframework Fe inside zeolite crystals, $\mathrm{Fe}_{\mathrm{Ox}, \mathrm{IN}}$,

(f) agglomerated extraframework Fe on the external surface, $\mathrm{Fe}_{\mathrm{Ox}, \mathrm{OUT}}$.

In what follows, we will discuss more in detail the different molecular structures.

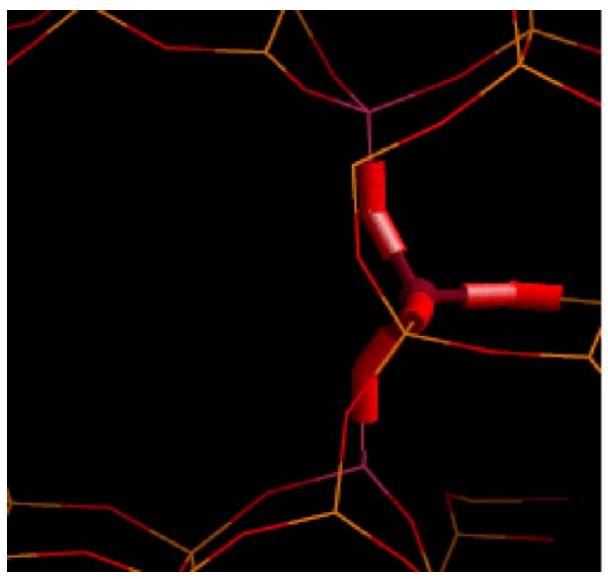

\subsubsection{Framework $\mathrm{Fe}, \mathrm{Fe}_{\mathrm{F}}$}

Fe/ZSM-5 prepared via the hydrothermal synthesis method should contain exclusively iron in zeolite framework positions, isomorphous substituting for silicon atoms. That implies that single iron atoms are well incorporated in the zeolite structure, are isolated, and in a tetrahedral surrounding of oxygen. The next nearest-neighbour atoms are silicon (or aluminium) atoms. The characterization techniques that display typical spectral features for $\mathrm{Fe}_{\mathrm{F}}$ ( $\mathrm{Fe} \mathrm{e}^{\mathrm{III}}$ in $\mathrm{T}_{\mathrm{d}}$ symmetry) and which are most widely used to prove its presence are EPR [17-19], Mössbauer [20-22] and XAFS [23,24].

\subsubsection{Mononuclear $\mathrm{Fe}, \mathrm{Fe}_{1}$}

The second type of single, isolated Fe sites can be found in extraframework positions and is called 'mononuclear'. At the cationic positions associated to the zeolite lattice $\mathrm{H}^{+}$is replaced by $\mathrm{Fe}$ ions and a chemical bond to zeolite oxygen atoms is effectuated. Probably the local surrounding by oxygen for iron in extraframework positions will deviate from a perfect symmetry. The occurrence of $\mathrm{Fe}_{1}$ sites as $\mathrm{Fe}^{\mathrm{III}}$ in both four and six-fold symmetry complicates the spectroscopic determination of the $\mathrm{Fe}_{1}$ species, as well as its distinction from $\mathrm{Fe}_{\mathrm{F}}$. Mössbauer spectroscopy in principle should be able to distinguish a perfect tetraeder (singlet) from one that is slightly distorted (doublet). However, the proximity of other framework iron atoms in case of a higher Fe loading may induce similar spectral features [25]. Also for EPR caution is recommended regarding the exclusive assignment of certain $g$-values to the presence of one particular species [26]. Even though EXAFS can provide detailed information on the local structure of materials it will be difficult to distinguish similar sites. It can be expected that extraframework $\mathrm{Fe}_{1}$ sites will be easier to reduce/oxidize than framework $\mathrm{Fe}_{\mathrm{F}}$ (Fig. 7).

\subsubsection{Binuclear $\mathrm{Fe}, \mathrm{Fe}_{2}$}

Chen and Sachtler proposed a binuclear oxygen bridged complex as the major active ingredient of Fe/ZSM-5 prepared

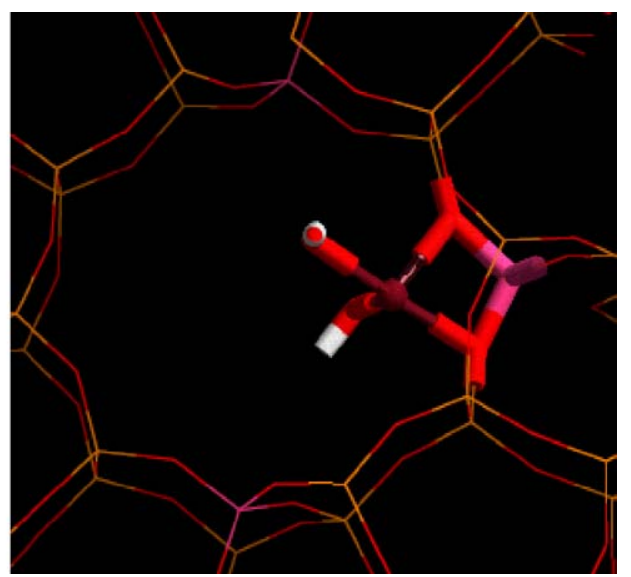

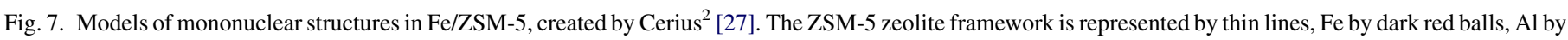

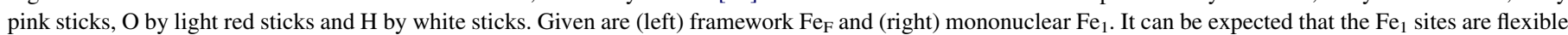

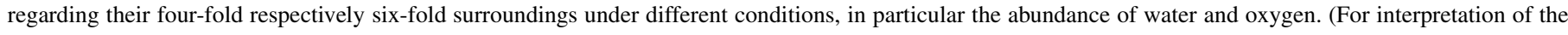
references to colour in this figure legend, the reader is referred to the web version of the article.) 
by chemical vapour deposition of $\mathrm{FeCl}_{3}$ [28]. A similar structure was reported before for copper containing ZSM-5 and the analogy with biological structures that also were able to perform oxygen transfer reaction was attractive. Arguments in favour of such iron oxo centres were the $\mathrm{Fe} / \mathrm{Al}$ ratio of 1 , indicating that the positive charge of iron was balanced partially by extraframework oxygen of a complex. In addition it was possible to carry out $\mathrm{CO}$ oxidations, in essence to be reduced through loss of oxygen. A fraction up to $20 \%$ was subject to reduction from $\mathrm{Fe}^{3+}$ to $\mathrm{Fe}^{2+}$ by the thermal release of $\mathrm{O}_{2}$ upon mere heating in helium (often indicated by autoreduction) to $600{ }^{\circ} \mathrm{C}$ [29].

In the past years numerous articles appeared on the identification of binuclear complexes by spectroscopic techniques and chemical probe reactions [1,2,30-39]. EXAFS studies have had a leading position for the characterization of these complexes. The detection of $\mathrm{Fe}-\mathrm{Fe}$ scattering, at a similar distance $(R \sim 3.0 \AA)$ and with a coordination number close to unity, strongly supported the hypothesis of $\mathrm{Fe}_{2}$ sites. The structural - and functional - resemblance with the active site of forms of MMO (the enzyme methane monooxygenase) was striking [40]. Also Mössbauer studies supported the existence of binuclear iron complexes [1,40]. Initially the presence of $\mathrm{Fe}_{2}$ sites was supposed just for overexchanged Fe/ZSM-5 prepared by the sublimation technique. However, the formation of these complexes is also assumed to occur upon activation treatments of Fe/ZSM-5 prepared by other routes. In contrast, the assumption that $\mathrm{Fe}_{2}$ sites are the only or most abundant species present in Fe/ZSM-5 samples is no longer supported in part of the recent literature [41,42] (Fig. 8).

\subsubsection{Oligomeric $\mathrm{Fe}, \mathrm{Fe}_{N}$}

EXAFS, Mössbauer and UV-vis experiments indicate that oligimeric species are formed as chains in the zeolite channels. This iron species is distinguished from binuclear species since the iron atoms are not necessarily close to aluminium sites (Fe/
$\mathrm{Al}>1$ ) as well as from iron oxide like phases because some reducibility is observed. It is suggested that oligomers may contribute to $\mathrm{N}_{2} \mathrm{O}$ decomposition albeit with a low reaction rate, but are not capable to oxidize hydrocarbons or even $\mathrm{CO}$ [43].

\subsubsection{Intrazeolitic agglomerated $\mathrm{Fe}, \mathrm{Fe}_{\mathrm{Ox}, \mathrm{IN}}$}

Within the zeolite structure small agglomerated iron phases can be formed that are less easy to reduce. The size of these $\mathrm{Fe}_{\mathrm{Ox}}$ particles is up to $2 \mathrm{~nm}$ and they cannot be observed by TEM. Their formation most likely is induced by severe activation treatments like calcination or steaming. Steaming creates voids and larger pores that may accommodate such particles. Intrazeolitic $\mathrm{Fe}_{\mathrm{Ox}}$ is distinct from oligomeric $\mathrm{Fe}_{\mathrm{N}}$ with respect to the extent of $\mathrm{Fe}-\mathrm{Fe}$ coordination, in other words its iron oxide-like nature is more pronounced. The images in Fig. 9 give the impression that the conversion of $\mathrm{Fe}_{\mathrm{N}}$ into $\mathrm{Fe}_{\mathrm{Ox}}$ is feasible.

\subsubsection{Zeolite surface Fe crystallites, $\mathrm{Fe}_{\mathrm{Ox} \text {, OUT }}$}

Small particles of $\mathrm{Fe}_{3} \mathrm{O}_{4}, \mathrm{FeOOH}$ and $\mathrm{Fe}_{2} \mathrm{O}_{3}$, are observed on the external zeolite surface of several Fe/ZSM-5 materials. Provided the particles formed are large enough iron oxide phases can be easily detected by XRD and TEM, in particular when combined with EDX or EELS. Also EXAFS and Mössbauer are able to detect for instance $\mathrm{Fe}_{2} \mathrm{O}_{3}$ if a significant fraction is present. $\mathrm{Fe}_{\mathrm{Ox}}$ originates for instance from that part of the iron precursor that is not well anchored during the preparation stage of post-synthesis Fe/ZSM-5 samples and subsequently is converted upon calcination. Some preparation routes yield more iron oxide like species than others; especially ion exchange from aqueous solutions is a notorious method. Also severe conditions applied in activation treatments like calcination and steaming promote the forming of $\mathrm{Fe}_{\mathrm{Ox}}$. Besides such phases represent inactive iron they most likely harm the activity by blocking of zeolite pores thus making active sites inaccessible.
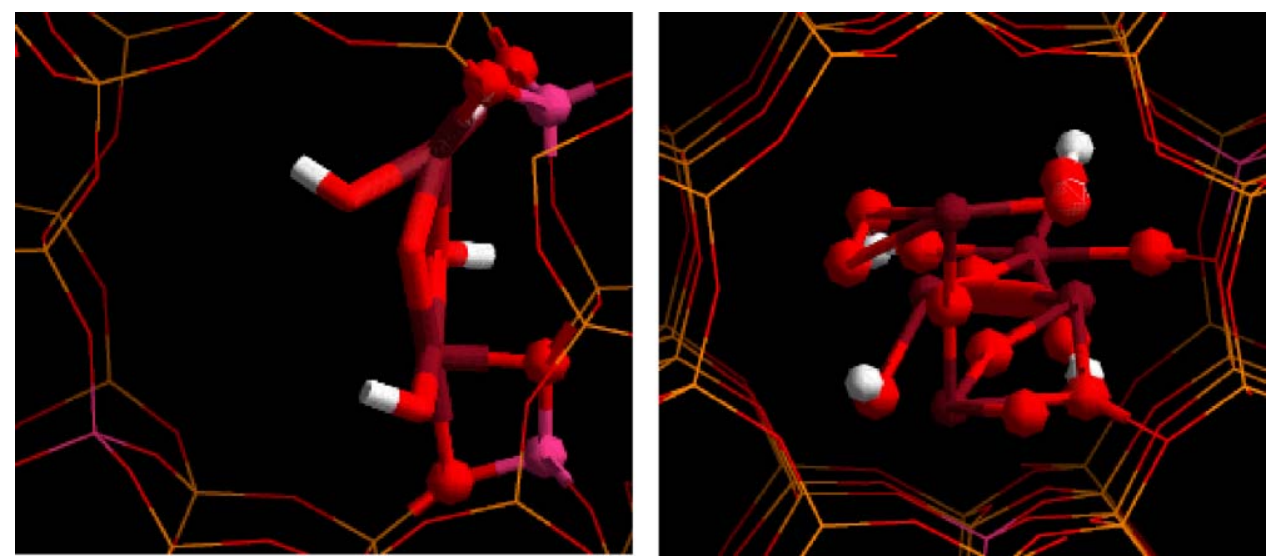

Fig. 8. Models of binuclear and oligomeric structures in Fe/ZSM-5, created by Cerius ${ }^{2}$ [27]. The ZSM-5 zeolite framework is represented by thin lines, Fe by dark red sticks/balls, $\mathrm{Al}$ by pink balls, $\mathrm{O}$ by light red sticks/balls and $\mathrm{H}$ by white sticks/balls. Given are (left) binuclear $\mathrm{Fe}_{2}$ and (right) oligomeric $\mathrm{Fe}_{\mathrm{N}}$. Both systems $\mathrm{Fe}_{2}$ and $\mathrm{Fe}_{\mathrm{N}}$ will be flexible regarding their four-fold respectively six-fold surroundings (and $\mathrm{Fe}^{\mathrm{II}}$ respectively $\mathrm{Fe}^{\mathrm{III}}$ valence) under different conditions, in particular the abundance of water and oxygen, where some irons in the $\mathrm{Fe}_{\mathrm{N}}$ system can be expected to be less accessible/flexible. (For interpretation of the references to colour in this figure legend, the reader is referred to the web version of the article.) 

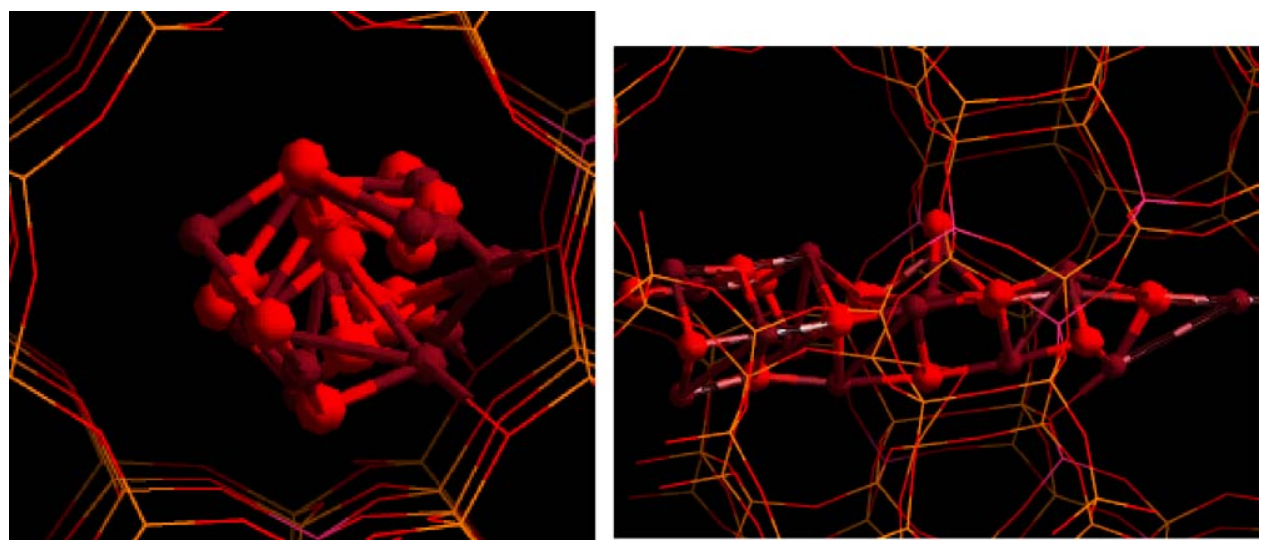

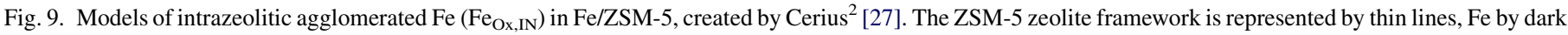

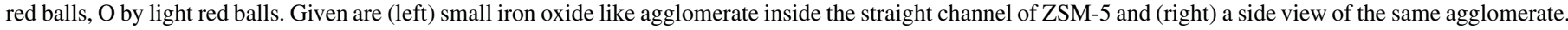

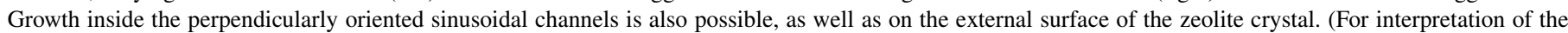
references to colour in this figure legend, the reader is referred to the web version of the article.)

\subsection{The nature of the iron species in Fe/ZSM-5 as determined by $X$-ray spectroscopy}

Table 6 contains the main results from the soft X-ray absorption, X-MCD, K $\beta$-XANES and EXAFS spectra. For the framework Fe/ZSM-5 samples the following picture appears. The am-Fe/ZSM-5 contains only isolated iron sites. The $t f-\mathrm{Fe} /$ ZSM-5 contains distorted four-fold iron sites that are, very likely, still isolated. They can be fitted as having 35\% six-fold Fe sites, in other words the distortion gives rise to a decrease of the pre-edge intensity equivalent to $35 \%$. Proton exchange increases the distortion, while the $\mathrm{X}-\mathrm{MCD}$ results show that $30 \%$ of the iron sites are no longer isolated but have another iron atom at close distance. These minority sites could not be isolated from the EXAFS analysis. The experimental evidence is not sufficient to specify the nature of these clusters: they could be $30 \%$ binuclear iron sites or a smaller amount of oligomers. The steamed $h s$-Fe/ZSM-5 sample shows clear evidence from oxide clusters. The similarity of the EXAFS spectra of $h s$-Fe/ZSM-5 to Fe/ZSM-5-sc indicates that the situation in these systems, respectively steamed frameworksubstituted and calcined overexchanged Fe/ZSM-5, is rather

Table 6

Main results for the studied samples

\begin{tabular}{|c|c|c|c|c|c|c|}
\hline Name & Results & $\mathrm{Fe}_{\mathrm{F}}$ & $\mathrm{Fe}_{1}$ & $\mathrm{Fe}_{2} / \mathrm{Fe}_{\mathrm{N}}$ & $\mathrm{Fe}_{\mathrm{Ox}}$ (in) & $\mathrm{Fe}_{\mathrm{Ox}}($ out $)$ \\
\hline \multicolumn{7}{|c|}{ Framework-substituted Fe/ZSM-5 ( $\mathrm{Si} / \mathrm{Al}=36 ; 0.3$ wt. $\% \mathrm{Fe})$} \\
\hline am-Fe/ZSM-5 & $100 \%$ isolated $(\mathrm{X}-\mathrm{MCD})$ & $\mathrm{X}$ & ? & & & \\
\hline$t f-\mathrm{Fe} / \mathrm{ZSM}-5$ & $\begin{array}{l}\text { Distorted four-fold (EXAFS), } \\
35 \% \text { six-fold Fe (K } \beta \text {-XANES). }\end{array}$ & $\mathrm{X}$ & $\mathrm{X}$ & & & \\
\hline$H$-Fe/ZSM-5 & $\begin{array}{l}30 \% \text { clusters (X-MCD), fitted } \\
\text { without Fe-neighbours (EXAFS), } \\
\text { strongly distorted four-fold (EXAFS), } \\
50 \% \text { six-fold Fe (K } \beta \text {-XANES) }\end{array}$ & $\mathrm{X}$ & $\mathrm{X}$ & $\mathrm{X}$ & & \\
\hline$h s-\mathrm{Fe} / \mathrm{ZSM}-5$ & $\begin{array}{l}50 \% \text { isolated }(\mathrm{X}-\mathrm{MCD}), \text { oxide } \\
\text { clusters + isolated sites (EXAFS); } \\
80 \% \text { six-fold } \mathrm{Fe}(\mathrm{K} \beta \text {-XANES })\end{array}$ & $\mathrm{X}$ & $\mathrm{X}$ & $\mathrm{X}$ & $\mathrm{X}$ & \\
\hline \multicolumn{7}{|c|}{ Overexchanged Fe/ZSM-5 (Si/Al = 17; 4.4 wt.\% Fe) } \\
\hline Fe/ZSM-5-Cl & Oxy-chloride 4-fold (EXAFS) & & $\mathrm{X}$ & & & \\
\hline $\mathrm{Fe} / \mathrm{ZSM}-5-\mathrm{H}_{2} \mathrm{O}$ & $\begin{array}{l}\text { Distorted six-fold oxygen (EXAFS); } \\
\text { homogeneous iron distribution (EELS) }\end{array}$ & & $\mathrm{X}$ & $?$ & & \\
\hline Fe/ZSM-5-mc & $\begin{array}{l}\text { Binuclear or oxide clusters }+ \text { isolated sites } \\
\text { (EXAFS); iron enrichment at surface } \\
\text { (EELS); six-fold } \mathrm{Fe}^{\mathrm{III}} \text { in oxygen with } \\
\text { weak } \mathrm{Fe}-\mathrm{O} \text { bonds; four-fold } \mathrm{Fe}^{\mathrm{II}} \text { in } \\
\mathrm{He} \text { at } 350{ }^{\circ} \mathrm{C} \text { (soft XAS) }\end{array}$ & & $\mathrm{X}$ & $\mathrm{X}$ & $\mathrm{X}$ & \\
\hline Fe/ZSM-5-sc & $\begin{array}{l}\text { Oxide clusters }+ \text { isolated sites } \\
\text { (EXAFS); } \mathrm{Fe}_{2} \mathrm{O}_{3} \text { particles on the outside } \\
\text { (EELS); strong oxidation and reduction } \\
\text { effects at } 25 \text { and } 350{ }^{\circ} \mathrm{C} \text { with average } \\
\text { valence systematically lower than } \\
\text { Fe/ZSM-5-mc (soft XAS) }\end{array}$ & & $\mathrm{X}$ & $\mathrm{X}$ & $\mathrm{X}$ & $\mathrm{X}$ \\
\hline
\end{tabular}

The last five columns give the occurrence of the various iron sites in the systems as determined by the X-ray characterization techniques applied. 
similar with a large fraction of the iron occurring in iron-oxide oligomers/clusters that occur inside the zeolite as well as on the outer surface. Still half the iron sites remain as isolated iron for $h s$-Fe/ZSM-5 samples.

The overexchanged Fe/ZSM-5 is homogeneously distributed in $\mathrm{Fe} / \mathrm{ZSM}-5-\mathrm{H}_{2} \mathrm{O}$ in distorted six-fold sites. Calcination tends to drive the iron out of the zeolite channels, where the $\mathrm{Fe} /$ ZSM-5-mc only shows iron enrichment and the Fe/ZSM-5-sc in addition shows $\mathrm{Fe}_{2} \mathrm{O}_{3}$ nanoparticles on the exterior of the zeolite crystals. Both the calcined samples show essentially sixfold $\mathrm{Fe}^{\mathrm{III}}$ sites in oxygen with weak $\mathrm{Fe}-\mathrm{O}$ bonds and four-fold $\mathrm{Fe}^{\mathrm{II}}$ sites in helium, where fast (partly) reversible oxidation and reduction effects are visible at both 25 and $350{ }^{\circ} \mathrm{C}$ with average valence systematically lower for Fe/ZSM-5-sc. This implies that under these conditions the iron-oxide clusters are not inert but also change show changes in their iron valence.

\section{Concluding remarks}

The results on Fe/ZSM-5 show that in situ soft X-ray absorption spectroscopy (sXAS) is a very powerful tool in catalyst characterization to study structural and electronic properties. The application benefits from the much higher resolution of soft X-rays compared with hard X-rays together with the relatively large, systematic variation of the spectral features in the metal $(\mathrm{Fe}) \mathrm{L}$ edge with the oxidation state. This analysis is assisted by the detailed simulation of the spectral shapes. These factors enabled a considerably higher precision in the determination of the average valence of iron, with a time resolution of $30 \mathrm{~s}$. However, because of the use of electron yield detection the technique is surface sensitive and the results reflect only the upper $4 \mathrm{~nm}$ of the sample.

We have shown that X-MCD is a very direct tool to determine the amount of isolated iron sites. In addition, the $\mathrm{L}$ edge spectra could be measured for the low-loaded samples due to fluorescence detection. Because the X-MCD measurements are performed in vacuum at $4 \mathrm{~K}$, this limits the application to these non-in situ conditions. We can conclude that X-MCD provides an important addition to the characterization tools for heterogeneous catalysts containing a (very) low concentration of transition metal ions, where we note that the technique is, in principle, applicable to all metals. Systems that contain only a single site can be analyzed in much more detail and one can obtain information regarding the (para)magnetic moments and from temperature and field dependent studies one can in addition determine the local exchange couplings for binuclear centres, etc. [10,44].

EELS spectra measured in a transmission electron microscope have the great advance of their unrivalled spatial resolution of $0.5 \mathrm{~nm}$. This provides direct access to measure the spectra of small isolated nanoparticles on the outside of zeolite crystals. The resolving power is not enough to see clusters inside the zeolite pores. A disadvantage of STEM-EELS is that the measurement needs UHV conditions, though progress is made towards measurements in the mbar range [45]. Another powerful tool of EELS measurements is the accurate determination of the elemental variations with $0.5 \mathrm{~nm}$ spatial resolution. A potential future experiment would be to study a zeolite crystal under a few mbar pressure and follow the iron movement towards the zeolite edges during the calcination procedure (in real time).

The measurement of the fluorescent $K \beta$ transition with a high-resolution spectrometer yields a range of new characterization techniques [46], including the high-resolution detection of the XANES region of the spectrum. These highresolution spectra enabled a refined analysis the pre-edge features. The application of ' $\mathrm{K} \beta$-detected XANES' made it possible to quantify the degree of iron extraction out of the zeolite framework as a function of the steaming treatment. K $\beta$ detected XANES is readily applicable to all other $3 \mathrm{~d}$ transition metal ions in loadings down to $0.1 \mathrm{wt}$. $\%$, possibly even lower. High quality in situ EXAFS data were obtained from $\mathrm{K} \alpha$ fluorescence detection. The high signal to noise ratio enabled a full EXAFS data-analysis including the higher coordination shells for these low loaded samples, where we remark that these EXAFS data are not different from normal EXAFS spectra.

In the near future, many new developments are to be expected. In situ soft $\mathrm{X}$-ray absorption and $\mathrm{K} \beta$-detected XANES have the potential to become 'standard' tools for catalysis research, similar to traditional XANES and EXAFS today. This would need the availability of experimental stations, where these techniques can be readily applied. XMCD will probably remain a rather specialized technique in the field of heterogeneous catalysis. New developments are for all to be expected from X-ray spectro-microscopy that promise in situ soft X-ray absorption and K $\beta$-detected XANES experiments with nanometer size spatial resolution [47].

\section{Acknowledgements}

We would like to thank Andrea Battiston for the preparation of the overexchanged samples, Kaveri Sawant and Raul Lobo (U, Delaware, USA) for the preparation of the frameworksubstituted samples. The STEM-EELS experiments have been performed in collaboration with Odile Stephan (LPS, Orsay, France) and the X-MCD experiments with Cinthia Piamonteze, Simon George and Steve Cramer (LBL, Berkeley, USA). We would like to thank Axel Knop-Gericke, Michael Hävecker, Ralf Mayer, Hendrik Bluhm, and Robert Schlögl (FHI, Berlin, Germany) for the in situ soft X-ray experiments and Pieter Glatzel (ESRF, Grenoble, France), Uwe Bergmann (SSRL, Stanford, USA) and Raul Barrea (APS, Argonne, USA) for the selective hard X-ray experiments.

\section{References}

[1] A.A. Battiston, J.H. Bitter, F.M.F. de Groot, A.R. Overweg, O. Stephan, J.A. Van Bokhoven, P.J. Kooyman, C. Van Der Spek, G. Vanko, D.C. Koningsberger, J. Catal. 213 (2003) 251-271.

[2] A.A. Battiston, J.H. Bitter, D.C. Koningsberger, J. Catal. 218 (2003) 163177.

[3] W.M. Heijboer, A.A. Battiston, A. Knop-Gericke, M. Havecker, H. Bluhm, B.M. Weckhuysen, D.C. Koningsberger, F.M.F. de Groot, Phys. Chem. Chem. Phys. 5 (2003) 4484-4491. 
[4] W.M. Heijboer, P. Glatzel, K.R. Sawant, R.F. Lobo, U. Bergmann, R.A. Barrea, D.C. Koningsberger, B.M. Weckhuysen, F.M.F. de Groot, J. Phys. Chem. B 108 (2004) 10002-10011.

[5] W.M. Heijboer, A.A. Battiston, A. Knop-Gericke, M. Havecker, R. Mayer, H. Bluhm, R. Schlogl, B.M. Weckhuysen, D.C. Koningsberger, F.M.F. de Groot, J. Phys. Chem. B 107 (2003) 13069-13075.

[6] A. Knop-Gericke, M. Havecker, T. Schedel-Niedrig, R. Schlogl, Catal. Lett. 66 (2000) 215-220.

[7] A. Knop-Gericke, M. Havecker, T. Schedel-Niedrig, R. Schlogl, Top. Catal. 10 (2000) 187-198.

[8] M. Abbate, J.B. Goedkoop, F.M.F. de Groot, M. Grioni, J.C. Fuggle, S. Hofmann, H. Petersen, M. Sacchi, Surf. Interf. Anal. 18 (1992) 6569.

[9] A.T. Young, V. Martynov, H.A. Padmore, J. Electron Spectrosc. Related Phenom. 103 (1999) 885-889.

[10] T. Funk, A. Deb, S.J. George, H. Wang, S.P. Cramer, Coord. Chem. Rev. 249 (2005) 3-30.

[11] C. Colliex, T. Manoubi, M. Gasgnier, L.M. Brown, Scann. Electron Microsc. (1985) 489-512.

[12] R. Fischetti, S. Stepanov, G. Rosenbaum, R. Barrea, E. Black, D. Gore, R. Heurich, E. Kondrashkina, A.J. Kropf, S. Wang, K. Zhang, T.C. Irving, G.B. Bunker, J. Synch. Radiat. 11 (2004) 399-405.

[13] U. Bergmann, S.P. Cramer, SPIE Proc. 3448 (1998) 198-209.

[14] P. Glatzel, U. Bergmann, Coord. Chem. Rev. 249 (2005) 65-95.

[15] W.M. Heijboer, PhD Thesis, 2005 (Chapter 5).

[16] M. Wilke, F. Farges, P.E. Petit, G.E. Brown, F. Martin, Am. Miner. 86 (2001) 714-730.

[17] M. Santhosh Kumar, M. Schwidder, W. Gruenert, A. Brueckner, J. Catal. 227 (2004) 384-397.

[18] P. Fejes, K. Lazar, I. Marsi, A. Rockenbauer, L. Korecz, J.B. Nagy, S. Perathoner, G. Centi, Appl. Catal. A: Gen. 252 (2003) 75-90.

[19] A.M. Ferretti, L. Forni, C. Oliva, A. Ponti, Res. Chem. Intermed. 28 (2002) 101-116.

[20] K. Lazar, A.N. Kotasthane, P. Fejes, Catal. Lett. 57 (1999) 171-177.

[21] N.S. Ovanesyan, A.A. Shteinman, K.A. Dubkov, V.I. Sobolev, G.I. Panov, Kinet. Catal. 39 (1998) 792-797.

[22] A.R. Overweg, M.W.J. Craje, A.M. van der Kraan, I. Arends, A. Ribera, R.A. Sheldon, J. Catal. 223 (2004) 262-270.

[23] E. Hensen, Q.J. Zhu, P.H. Liu, K.J. Chao, R. van Santen, J. Catal. 226 (2004) 466-470.

[24] S. Bordiga, R. Buzzoni, F. Geobaldo, C. Lamberti, E. Giamello, A. Zecchina, G. Leofanti, G. Petrini, G. Tozzola, G. Vlaic, J. Catal. 158 (1996) 486-501.
[25] J.B. Taboada, A.R. Overweg, M.W.J. Craje, I.W.C.E. Arends, G. Mul, A.M.V.D. Kraan, Micropor. Mesopor. Mater. 75 (2004) 237-246.

[26] D. Goldfarb, M. Bernardo, K.G. Strohmaier, D.E.W. Vaughan, H. Thomann, J. Am. Chem. Soc. 116 (1994) 6344-6353.

[27] Cerius $^{2}$ (1999) is a Modeling and Simulation Software Package, Molecular Simulations Inc. (MSI), which is now Accelrys. See http://www. accelrys.com/cerius2/.

[28] H.Y. Chen, W.M.H. Sachtler, Catal. Today 42 (1998) 73-83.

[29] T.V. Voskoboinikov, H.Y. Chen, W.M.H. Sachtler, Appl. Catal. B: Environ. 19 (1998) 279-287.

[30] A.A. Battiston, J.H. Bitter, W.M. Heijboer, F.M.F. de Groot, D.C. Koningsberger, J. Catal. 215 (2003) 279-293.

[31] H.Y. Chen, T. Voskoboinikov, W.M.H. Sachtler, J. Catal. 180 (1998) 171183.

[32] H.Y. Chen, T. Voskoboinikov, W.M.H. Sachtler, Catal. Today 54 (1999) 483-494.

[33] E.M. El-Malki, R.A. Van Santen, W.M.H. Sachtler, J. Catal. 196 (2000) 212-223.

[34] E.J.M. Hensen, Q. Zhu, M.M.R.M. Hendrix, A.R. Overweg, P.J. Kooyman, M.V. Sychev, R.A. van Santen, J. Catal. 221 (2004) 560-574.

[35] F. Heinrich, C. Schmidt, E. Loffler, M. Menzel, W. Grunert, J. Catal. 212 (2002) 157-172.

[36] P. Marturano, L. Drozdova, G.D. Pirngruber, A. Kogelbauer, R. Prins, Phys. Chem. Chem. Phys. 3 (2001) 5585-5595.

[37] P. Marturano, A. Kogelbauer, R. Prins, J. Catal. 190 (2000) 460-468.

[38] G.D. Pirngruber, P.K. Roy, N. Weiher, J. Phys. Chem. B 108 (2004) 13746-13754.

[39] K.S. Pillai, J.F. Jia, W.M.H. Sachtler, Appl. Catal. A: Gen. 264 (2004) 133-139.

[40] K.A. Dubkov, N.S. Ovanesyan, A.A. Shteinman, E.V. Starokon, G.I. Panov, J. Catal. 207 (2002) 341-352.

[41] K.S. Pillai, J.F. Jia, W.M.H. Sachtler, Appl. Catal. A: Gen. 264 (2004) 133-139.

[42] J.F. Jia, K.S. Pillai, W.M.H. Sachtler, J. Catal. 221 (2004) 119-126.

[43] I. Yuranov, D.A. Bulushev, A. Renken, L. Kiwi-Minsker, J. Catal. 227 (2004) 138-147.

[44] J. Christiansen, G. Peng, A.T. Young, L.B. LaCroix, E.I. Solomon, S.P. Cramer, Inorg. Chim. Acta 243 (1996) 229-232.

[45] J.B. Wagner, P.L. Hansen, A.M. Molenbroek, H. Topsoe, B.S. Clausen, S. Helveg, J. Phys. Chem. B 107 (2003) 7753-7758.

[46] F. de Groot, Chem. Rev. 101 (2001) 1779-1808.

[47] I.J. Drake, T.C.N. Liu, M. Gilles, T. Tyliszczak, A.L.D. Kilcoyne, D.K. Shuh, R.A. Mathies, A.T. Bell, Rev. Sci. Instrum. 75 (2004) 3242-3247. 